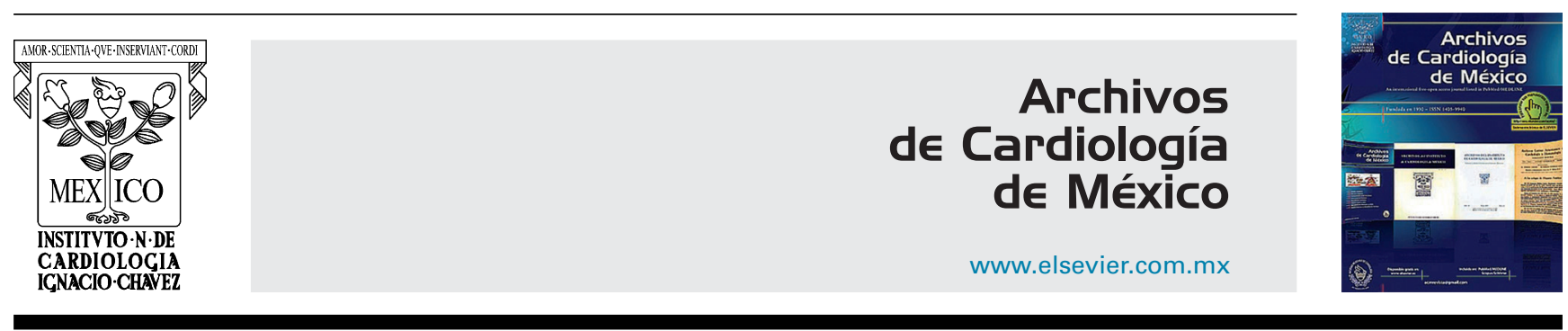

IMAGEN EN CARDIOLOGÍA

\title{
Invasión auricular masiva por carcinoma broncogénico complicada con ictus
}

\section{Massive atrial invasion by bronchogenic carcinoma complicated with stroke}

\author{
Delicia I. Gentille Lorente*
}

Servicio de Cardiología, Hospital Verge de la Cinta, Institut d'Investigació Sanitària Pere Virgili (IISPV), Tortosa, Tarragona, España

Recibido el 25 de agosto de 2017; aceptado el 27 de febrero de 2018

La mayoría de los tumores cardiacos secundarios corresponden a metástasis de cáncer de pulmón; su diseminación a corazón o pericardio ocurre, en orden de frecuencia, vía linfática, vía hemática, o por contigüidad o vía transvenosa pulmonar.

Se presenta el caso de un varón de 51 años, fumador y enólico, que consultó a urgencias por tos, disnea y edemas en piernas, progresivos, y de 2 meses de evolución. Al examen físico destacaba la existencia de caquexia, hipofonesis pulmonar derecha a la auscultación y edemas en extremidades inferiores con fóvea; la analítica inicial y el electrocardiograma no mostraron alteraciones significativas $\mathrm{y}$, radiológicamente, destacó la presencia de un derrame pleural (DP) derecho severo (fig. 1A); mediante toracocentesis se drenaron $1.800 \mathrm{ml}$ de un líquido pleural seroso. Para descartar el origen cardiogénico del cuadro se realizó una ecocardiografía (fig. 1B), detectándose la existencia de una masa retrocardíaca heterogénea (siendo esto sugestivo de la existencia de necrosis y/o hemorragia intratumoral) de 11,8 $\times 11 \mathrm{~cm}$ de diámetro; dicha masa invadía

\footnotetext{
* Autor para correspondencia. Calle Esplanetes n. ${ }^{\circ} 14,43500$ Tortosa, Tarragona, España.

Correo electrónico: dgentille.ebre.ics@gencat.cat
}

las tres cuartas partes de la cavidad de la aurícula izquierda (AI), quedando abolido el drenaje de la vena pulmonar inferior derecha (VpID), y casi la mitad de la de la aurícula derecha $(A D)$, y presentaba masas móviles en superficie; también se documentó hipertensión pulmonar, elevación de la presión venosa central y la ausencia de derrame pericárdico. La tomografía computarizada (figs. 1C y D) confirmó la existencia de un DP derecho severo, e izquierdo mínimo, y de un gran tumor pulmonar que ocupaba el lóbulo inferior derecho (LID) y englobaba y colapsaba el bronquio intermediario y sus ramas; dicho tumor era heterogéneo y obliteraba gran parte de la $A D$, pero casi la totalidad de la Al, constatándose la ausencia de permeabilidad de la VpID.

El paciente ingresó para estudio bajo tratamiento sintomático diurético de asa en perfusión endovenosa, oxigenoterapia y anticoagulación con heparina de bajo peso molecular subcutánea ( $1 \mathrm{mg} / \mathrm{kg} / 12 \mathrm{~h})$. El estudio del líquido pleural evidenció que se trataba de un exudado linfocitario, sugestivo de inflamación crónica, y sin células malignas, y la broncoscopia que, a nivel del bronquio intermediario, existía una lesión oclusiva y aparentemente neoplásica mostrando su histología un carcinoma de células escamosas bien diferenciado. Durante el ingreso el paciente presentó clínica de focalidad neurológica; la resonancia magnética cerebral confirmó la existencia de un infarto isquémico agudo 


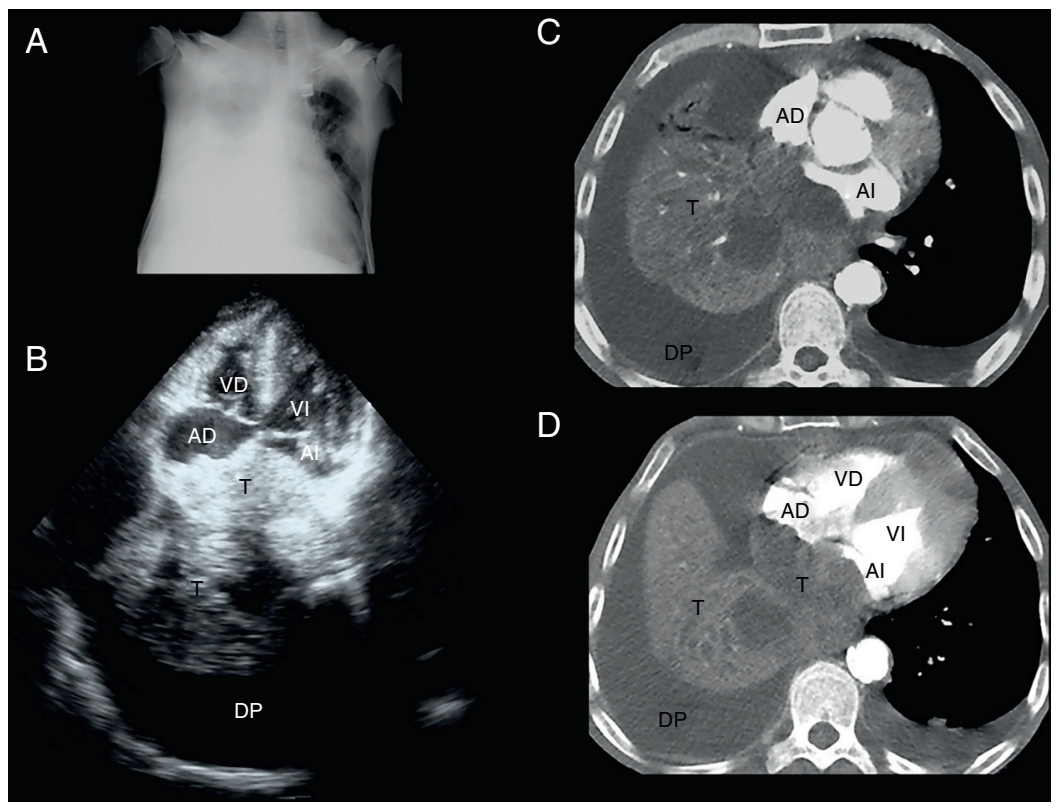

Figura 1 A) Radiografía de tórax: derrame pleural derecho masivo. B) Ecocardiografía transtorácica: en plano apical 4 cámaras se objetiva la existencia de una gran masa retrocardíaca heterogénea que invade las aurículas. C y D) Tomografía computarizada: se confirma la existencia de un tumor retrocardíaco que invade masivamente las aurículas en ausencia de derrame pericárdico. $\mathrm{AD}$ : aurícula derecha; Al: aurícula izquierda; DP: derrame pleural; T: tumor; VD: ventrículo derecho; VI: ventrículo izquierdo.

parietal derecho que, en este contexto y tras descartar la existencia de enfermedad a nivel de troncos supraaórticos, se consideró cardioembólico. Con diagnóstico final de carcinoma epidermoide de pulmón del LID estadio IV, con mal pronóstico a muy corto plazo del paciente, se optó por un tratamiento sintomático.

El caso presentado constituye una rareza ${ }^{1,2}$ al tratarse de un tumor cardiaco secundario a un carcinoma de pulmón que invade la Al de forma masiva por contigüidad (vía transvenosa pulmonar) y, posteriormente, también la AD. Y es que, en general, la extensión neoplásica por contigüidad supone la afectación del pericardio, causando pericarditis, derrame pericárdico e incluso taponamiento cardiaco; sin embargo, en las raras ocasiones en que dicha extensión parte de la contigüidad anatómica del hilio pulmonar con las venas pulmonares, la invasión es directa al miocardio y al endocardio afectando, principalmente, al endocardio de la Al y, ocasionalmente, al de la AD o al de los ventrículos.

\section{Financiación}

No se recibió patrocinio de ningún tipo para llevar a cabo este artículo.

\section{Conflicto de intereses}

El autor declara no tener ningún conflicto de intereses.

\section{Bibliografía}

1. Lin MT, Ku SC, Wu MZ, et al. Intracardiac extension of lung cancer via the pulmonary vein. Thorax. 2008;63:1122.

2. Ballo $P$, Laureano R, Briganti $M$, et al. Left atrial mass invasion from pulmonary neoplasm extension via the right upper pulmonary vein presenting as ipsilateral stroke. Case Rep Med. 2016;2016, 708423470842346. 